\title{
Fast and Accurate Model for Optimization-based Design of Fractional-Slot Surface PM Machines
}

\author{
Benjamin Cheong \\ Power Electronics, Machine and \\ Control Group (PEMC), The \\ University of Nottingham, UK \\ eexbc4@nottingham.ac.uk \\ Michael Galea \\ Power Electronics, Machine and \\ Control Group (PEMC), The \\ University of Nottingham, UK \\ ezzmg@nottingham.ac.uk
}

\author{
Paolo Giangrande \\ Power Electronics, Machine and \\ Control Group (PEMC), The \\ University of Nottingham, UK \\ ezzpg@nottingham.ac.uk \\ Pericle Zanchetta \\ Power Electronics, Machine and \\ Control Group (PEMC), The \\ University of Nottingham, UK \\ eezpz@nottingham.ac.uk
}

\author{
Xiaochen Zhang \\ Power Electronics, Machine and \\ Control Group (PEMC), The \\ University of Nottingham, UK \\ ezzxz2@nottingham.ac.uk
}

Patrick Wheeler

Power Electronics, Machine and Control Group (PEMC), The University of Nottingham, UK eezpww@nottingham.ac.uk

\begin{abstract}
This paper presents the development and validation of a fast, accurate, and high dimensional Multiphysics analytical model for the optimization-based design of fractionalslot surface permanent magnet (PM) machines. The approach is non-iterative and high dimensional, i.e. considers a high number of input parameters. The resulting model takes an average of 0.03 seconds to run on a standard $P C$, and its accuracy is verified by both Finite Element (FE) analysis and experimental tests. Due to its accuracy and speed, the model can be easily integrated within a design optimization environment.
\end{abstract}

Keywords- Permanent Magnet Synchronous Machine, Electrical Machine Modelling, Design Optimization

\section{INTRODUCTION}

For aerospace applications where power density and efficiency are key requirements, the use of fractional-slot surface PM machine with concentrated windings is highly attractive $[1,2]$. The design of such machines is multiobjective in nature, and these objectives are often traded off against each other within an optimization environment. Significant research has been carried out, over the past decade, on methods to perform machine design optimizations more reliably and efficiently [3].

Finite element (FE) analysis is the principal tool in industry for accurate machine modelling and is occasionally incorporated within an optimization environment [4, 5]. However, this modelling approach demands high computational power, limiting the number of evaluations in each optimization run.

For better computational efficiency, an analytical approach to machine modelling is often preferred. For example, analytical electromagnetic models have been introduced in [6] and [7] for PM machines, while analytical thermal models have been presented in $[8,9,10]$.

This paper proposes a simple yet comprehensive analytical surface PM machine model that considers both its electromagnetic and thermal behaviours. The model evaluates machine electromagnetic performance by calculating the air-gap magnetic field distribution and employing mathematical MMF winding functions. Further, the machine thermal behaviour is predicted using a simplified 2D Lumped Parameter Thermal Network (LPTN). The resulting model is characterized by a low computational time, achieved by its non-iterative approach. FE analysis and experimental tests also reveal that good accuracy is achieved with this analytical

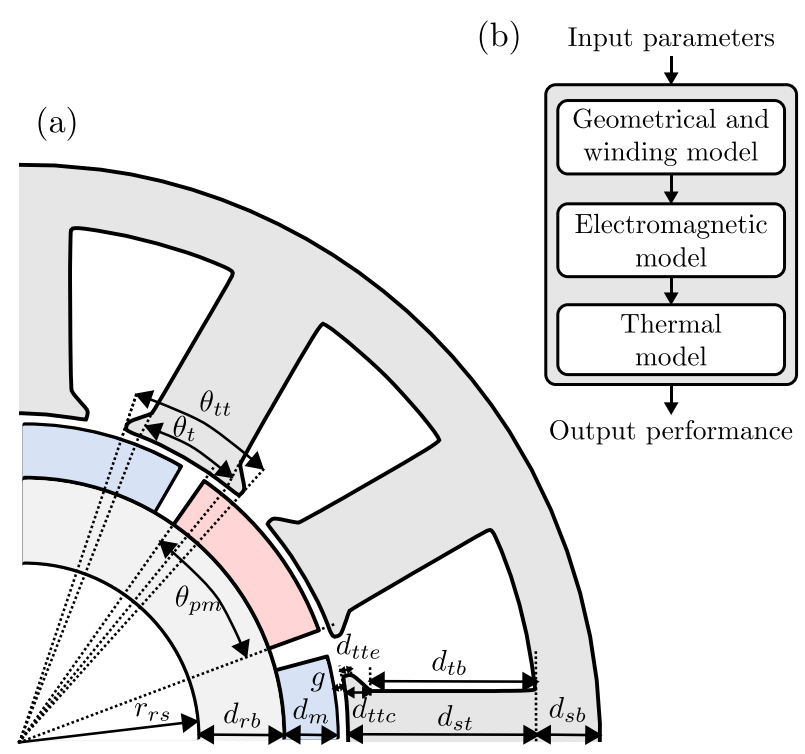

Fig. 1: (a) Geometrical input parameters for a typical surface PM machine. (b) Flowchart of machine model.

model. The speed and accuracy of this model make it particularly suitable for use in an optimization-based design.

\section{INPUT PARAMETER DEFINITIONS}

A total of 20 input parameters $D_{\text {in }}$ are defined for the machine model:

$$
D_{\text {in }} \ni\left\{P, S_{s}, G, N_{t s}, w_{d i a}, n_{w p c}, \omega_{r e}, i_{d}, i_{q}\right\}
$$

where $P$ is the pole number, $S_{S}$ is the slot number, $G$ is a set of machine geometrical parameters, $N_{t s}$ is the number of turns, $w_{\text {dia }}$ is the strand diameter, and $n_{w p c}$ is the number of strands per conductor, $\omega_{r e}$ is the electrical speed, $i_{d}$ is the daxis current, and $i_{q}$ is the q-axis current. The geometrical parameters contained in $G$ are:

$$
G \ni\left\{r_{r s}, d_{r b}, d_{m}, g, d_{t t c}, d_{t t e}, d_{t b}, d_{s b}, \theta_{t}, \theta_{t t}, \theta_{p m}, l\right\}
$$

where $l$ is the machine axial length, and the other parameters can be seen in Fig. 1(a) for a typical surface PM machine.

\section{PM MACHINE ANALYTICAL MODELLING}

In this section, details of the fractional-slot surface-PM machine model are presented. The flowchart of the model is 
TABLE I

WINDING FUNCTION AND FUNDAMENTAL WINDING FACTORS FOR DIFFERENT MACHINE SLOT-POLE COMBINATIONS

\begin{tabular}{c|c|c}
\hline $\begin{array}{c}\text { Slot pole } \\
\text { combinations }\end{array}$ & Winding function, $W_{n}^{*}$ & $\begin{array}{c}\text { Fundamental } \\
\text { winding factor }\end{array}$ \\
\hline $6 / 4,6 / 8$ & $\frac{P}{c} \frac{2}{n \pi} \sin \left(\frac{n \pi}{S_{s}}\right)$ & 0.866 \\
\hline $12 / 10,12 / 14$ & $\frac{P}{c} \frac{2}{n \pi} \sin \left(\frac{n \pi}{S_{s}}\right)\left[2 \cos \left(\frac{7 n \pi}{S_{s}}\right)\right]$ & 0.933 \\
\hline $18 / 14,18 / 22$ & $\frac{P}{c} \frac{2}{n \pi} \sin \left(\frac{n \pi}{S_{s}}\right)\left[1+2 \cos \left(\frac{10 n \pi}{S_{s}}\right)\right]$ & 0.902 \\
\hline $18 / 16,18 / 20$ & $\frac{P}{c} \frac{2}{n \pi} \sin \left(\frac{n \pi}{S_{s}}\right)\left[1-2 \cos \left(\frac{2 n \pi}{S_{s}}\right)\right]$ & 0.945 \\
\hline
\end{tabular}

simple as it only consists of three stages, as outlined in Fig. 1(b).

\section{A. Geometrical and Winding modelling}

To parameterize the machine geometry, an approach similar to [6] is employed. With input parameters defined in (2), the full geometry of a PM machine can be found and quantities of interest, such as slot area and stator core volume, are calculated.

Winding functions $W_{n}^{*}$ are employed to mathematically represent optimal winding layouts for different machine slot-pole combinations. These mathematical functions are defined as air-gap MMF produced by single-phase winding coils of 1 turn and carrying 1A current. By applying a Fourier series transformation on the winding function, the amplitude of each individual harmonic component, also known as winding factor, can be found. The winding function expressions and fundamental winding factor for a set of slot-pole combinations are given in Table I. With input parameters defined in (1), winding-related quantities of interest, such as winding length and resistance, are determined at this stage.

\section{B. Electromagnetic Modelling}

To evaluate the electromagnetic performance of an electrical machine, knowledge of the field distribution is required as it reveals where the flux is concentrated, where electric potential is created, and where force is produced. The surface PM machine electromagnetic model is based on its airgap magnetic field distribution.

\section{1) Open-circuit Air-Gap Magnetic Field}

The machine is firstly characterized by its open-circuit air-gap magnetic field using the technique in [11]. The magnetic field in the air-gap region is calculated in 2D polar coordinates, by solving the governing Laplacian/quasiPoissonian field equations. The assumptions here are that the stator and rotor cores feature infinite permeability and that the PM magnetic flux is uniformly distributed across the PM material. To account for stator slotting effects, a complex permeance method is employed, based on conformal transformations of the stator slot openings [12].

Next, flux flowing in the stator main magnetic path is found by integrating air-gap flux density over a tooth pitch and, subsequently, the induced winding flux linkages are

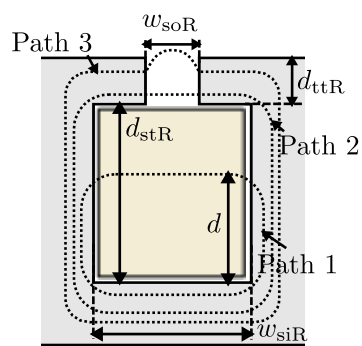

(a)

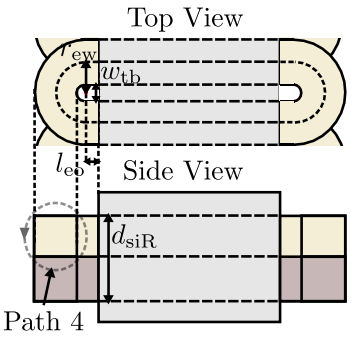

(b)
Fig. 2: Leakage flux paths in the (a) stator slot (b) end-winding.

calculated with the help of the winding function. By taking a negative derivative of the induced flux linkages, not only the fundamental component, but the full open-circuit back-electromotive force (BEMF) is obtained.

\section{2) Armature-reaction Air-Gap Magnetic Field}

A similar approach is employed to calculate the armaturereaction air-gap magnetic field, where the Laplacian equation is solved in the air-gap region for distributed current sheets on the stator surface. The current sheets have their lengths equal to the size of the slot opening and represent slots containing current-carrying conductors. To account for stator slotting effects, the complex slot permeances calculated previously are used again [13].

Armature-reaction air-gap magnetic field distribution is required for the calculation of magnetizing flux, magnetizing flux linkage and magnetizing inductance.

\section{3) Leakage Inductances}

Leakage inductance flux, defined as the armature-reaction flux that does not cross the air-gap, can be calculated with an energy method, also known as the principle of virtual work. According to this principle, the stored magnetic energy $W_{\phi}$ within a closed volume $V$ is equal to the field energy created by current-carrying winding enclosed within the volume. Therefore, the magnetic inductance of the volume $L_{v}$ can be calculated as:

$$
L_{V}=\frac{2 W_{\phi}}{i^{2}}=\frac{1}{\mu i^{2}} \int_{V} B^{2} d V
$$

where $i$ is the winding current, $\mu$ is the magnetic permeability of enclosed volume, and $B$ is the magnetic flux density. Assuming an infinite permeability of the stator core, slot inductances depend on the enclosed volume of air at the slot opening or coil within the slot. As illustrated in Fig. 2, leakage flux is considered to flow in four main paths:

- Path 1: Horizontally across inner slot walls

- Path 2: Horizontally between tooth tips at slot opening

- Path 3: Fringing between tooth tips at slot opening

- Path 4: Circularly around end-winding coils

Slot leakage inductances due to leakage flux flowing in paths 1,2, and 3 are computed with leakage permeance factors defined in [14]. The concentrated winding end-sections are considered as half air-core solenoids when viewed from the top, and their inductances are found using well-known equations for air-core solenoids. 


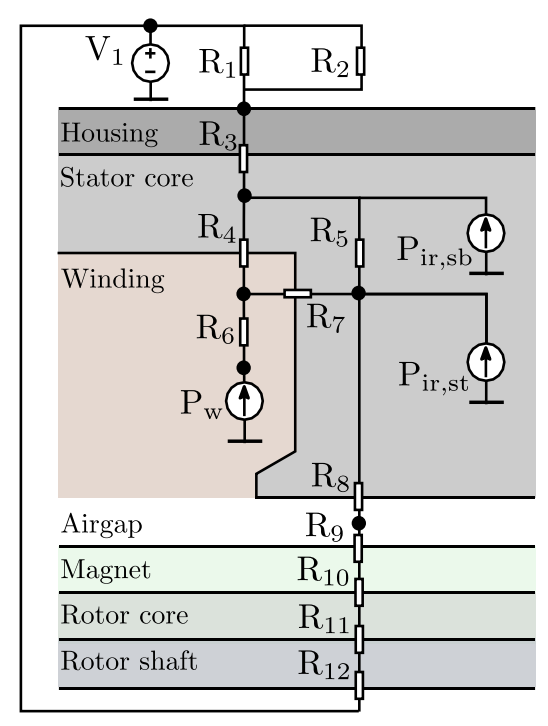

Fig. 3: Simplified 2D-Lumped Parameter Thermal Network.

\section{4) Flux and Flux Density Estimations}

With the large effective air-gap of surface PM machines, flux within the rotor core consists mainly of the PM flux. Flux density distribution at the rotor core surface is integrated across the surface area of a magnet pole to calculate the flux flowing into or out of the rotor core.

On the other hand, the stator core flux has a significant armature-reaction flux and leakage flux components, in addition to the PM flux. The sum of these extra flux components can be found as:

$$
\phi_{a r, p h}(t, \theta)=\frac{W_{p h}^{*}(\theta)\left(L_{m}+L_{s t}\right) i_{p h}(t)}{N_{t s}}
$$

where $W_{p h}^{*}(\theta)$ is the winding function, $L_{m}$ is the magnetizing inductance, $L_{s t}$ is the slot leakage inductances, $i_{p h}(t)$ is the instantaneous phase current, and $N_{t s}$ is the number of turns in series per phase. The total flux going through each stator tooth can, therefore, be computed by super-positioning $\phi_{a r, p h}(\theta)$ with the open-circuit PM flux. For double layer windings, the stator tooth flux is assumed to split equally, in opposite directions, as it enters the back-iron.

Rotor back-iron, stator tooth, and stator back-iron flux densities are calculated by dividing the respective flux over the area perpendicular to its direction of flow.

\section{5) Fundamental Magnetic Loss Estimations}

In general, iron losses contribute the largest share of machine losses under no-load conditions, as compared to mechanical losses. For estimation of fundamental iron losses in the soft ferromagnetic material, a two-terms approach is employed, based on the modified Steinmetz equation. Assuming a sinusoidally varying stator flux density, the specific loss $W_{\text {loss }}$ parameter $(\mathrm{W} / \mathrm{kg})$ for a certain material can be calculated as

$$
W_{\text {loss }}(f, \hat{B})=K_{\text {hys }} f^{\alpha} \hat{B}^{\beta}+K_{\text {eddy }}\left(K_{s f} f \hat{B}\right)^{2}
$$

where $\hat{B}$ is the peak amplitude and $f$ the frequency of the stator flux density, $K_{s f}$ is the stacking factor of the lamination sheets. $K_{\text {hys }}, \alpha, \beta$, and $K_{\text {eddy }}$ are Steinmetz coefficients obtained by curve-fitting manufacturers loss data. Loss
TABLE II

12S10P PROTOTYPE MACHINE PARAMETERS

\begin{tabular}{c|c|c}
\hline Parameters & Value & Unit \\
\hline Rated mechanical speed & 1500 & $\mathrm{rpm}$ \\
\hline Rated output power & 1300 & $\mathrm{~W}$ \\
\hline Rated phase current & 9.33 & $\mathrm{~A}$ \\
\hline No. of turns per coil & 30 & - \\
\hline Stack length & 54 & $\mathrm{~mm}$ \\
\hline Stator outer radius & 61 & $\mathrm{~mm}$ \\
\hline Stator \& rotor core material & $\mathrm{M} 235-35 \mathrm{~A}$ & - \\
\hline Permanent magnet material & $\mathrm{NdFe} 38-\mathrm{EH}$ & - \\
\hline
\end{tabular}

contributions from stator tooth and back-iron are considered separately as their flux densities values are different.

As air-gap magnetic flux fundamental component rotates synchronously with the rotor, no fundamental iron losses are produced in the rotor back-iron and magnets [15].

\section{6) Electromagnetic Torque}

To calculate electromagnetic torque, an energy method, also known as the principle of virtual work, is employed due to its simplicity compared to the Lorentz method and Maxwell stress tensor method. Average torque $T_{e}$ can be calculated as

$$
T_{e}=\frac{P_{\text {out }}}{\omega_{r m}}=\frac{P_{\text {in }}-P_{w}-P_{\text {ir }}-P_{m l}}{\omega_{r m}}
$$

where $P_{\text {out }}$ is the mechanical output power, $\omega_{r m}$ is the mechanical speed in radians, $P_{i n}$ is the input power, $P_{w}$ is the winding loss, $P_{i r}$ is the iron loss, and $P_{m l}$ is the mechanical loss. $P_{\text {in }}$ can be determined as:

$$
P_{\text {in }}=\frac{3 p}{2} \widehat{\Psi}_{d} \omega_{r m} \hat{\imath}_{q}
$$

where $p$ is the pole pair number, $\widehat{\Psi}_{d}$ is the peak d-axis flux linkage, and $\hat{l}_{q}$ is the peak q-axis stator current.

\section{Thermal Modelling}

During the design, thermal checks are in place to prevent machine performance derating due to over-temperatures, which might lead to wire insulation, degradation, and/or magnet demagnetization [16]. For this purpose, a simplified LPTN with a reduced number of thermal nodes [17] is employed, as illustrated in Fig. 3. As only steady-state temperatures are needed, thermal capacitances are omitted from the thermal network. Further, only the radial heat flow is modelled here [18].

Power loss in different parts of the machine are considered to inject heat flow into the relevant nodes, and the resulting node potential represents the physical temperature. The LPTN is solved within the model using a closed symbolic solution to predict temperatures in the slot and permanent magnet as they typically have much lower safe operating temperatures.

\section{MODEL VerificATIONS}

The developed machine analytical model is verified through FE analysis and experimental tests, on a prototype 12slot 10-pole surface PM machine. The machine parameters are listed in Table II. 


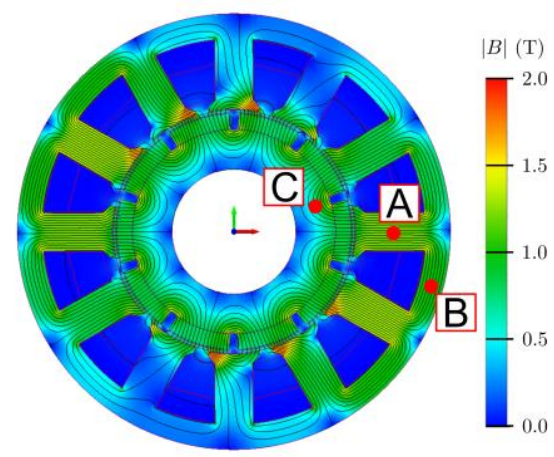

Fig. 4: FE static field solution under rated load conditions.

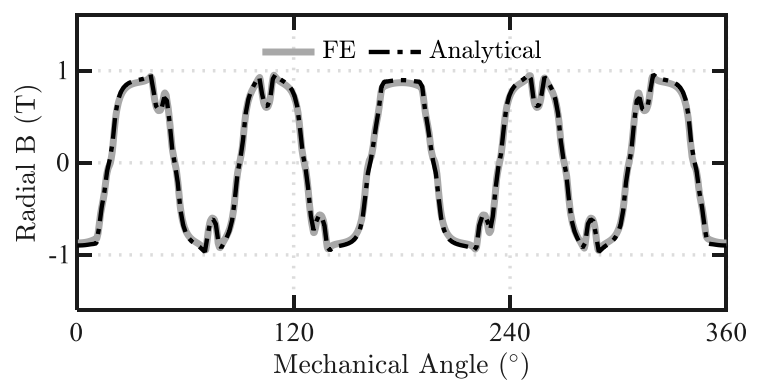

(a)

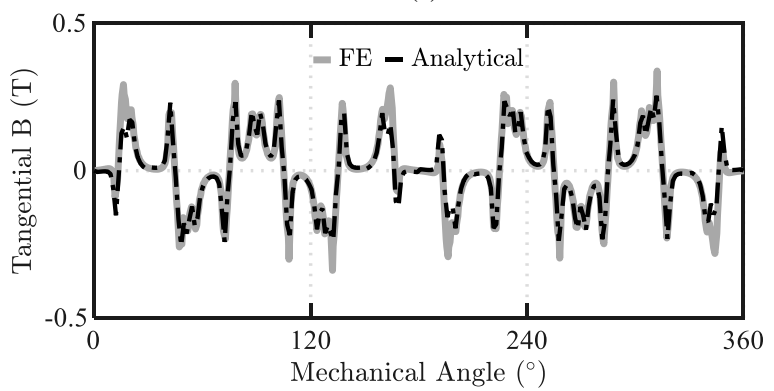

(b)

Fig. 5:(a) Radial and (b) tangential flux density components around the machine air-gap circumference.

\section{A. Finite Element Analysis}

In the analytical model, local saturation effects are not accounted for, and the core material is assumed to be infinitely permeable. FE analysis under static and transient with motion conditions are performed using Infolytica MagNet to check the validity of these assumptions for the prototype machine.

Fig. 4 shows static field solutions for the machine under rated-current conditions. The analytical model predicts a stator tooth flux density (Point A) of $1.46 \mathrm{~T}$, while the FE predicts $1.40 \mathrm{~T}$ (4.1\% difference); for the stator back-iron (Point $\mathrm{B}$ ), the analytical prediction is $1.15 \mathrm{~T}$, whereas the FE prediction is $1.13 \mathrm{~T}$ (1.7\% difference); finally, in the rotor back-iron (Point $\mathrm{C}$ ), the analytical prediction is $0.71 \mathrm{~T}$ while the FE prediction is $0.65 \mathrm{~T}$ ( $8.5 \%$ difference). The differences are due to local saturation, tooth-tip fringing flux, and nonuniform field distributions which are not considered in the analytical model.

The radial and tangential flux density components around the air-gap circumference are also extracted from the static field solution for comparison with the analytical model. As can be seen in Fig. 5, an excellent match between the waveforms is achieved, especially in the modelling of stator slotting effects. The consideration of stator-slotting effect is

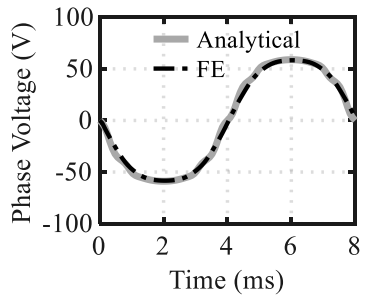

(a)

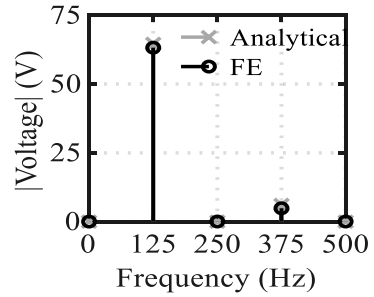

(b)

Fig.6: Open-circuit BEMF per phase at rated speed.

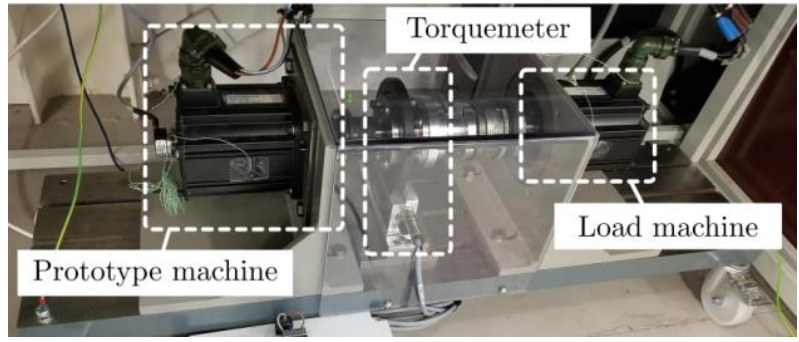

Fig. 7: Experimental test bench employed for model verifications.

particularly important for fractional slot machines, as their slot opening to pole pitch ratio is relatively large.

Through a transient with motion FE analysis, the BEMF and average electromagnetic torque are found. At rated speed and open-circuit conditions, Fig. 6 compares the BEMFs from the analytical and FE analysis, revealing a good match even in taking account of the third harmonics. At rated speed and rated load condition, the analytical model predicts an $8.49 \mathrm{Nm}$ torque, while the average torque from the $\mathrm{FE}$ analysis is equal to $8.41 \mathrm{Nm}$ (1.0\% difference), also showing an accurate match.

Finally, machine inductances are determined using results from the transient analysis. As only a $2 \mathrm{D} \mathrm{FE}$ analysis is performed, the FE end-winding inductance is set to be the same with the analytical model. As a result, the analytical model predicts an inductance value of $2.22 \mathrm{mH}$, while the FE model gives $2.28 \mathrm{mH}$ ( $2.7 \%$ difference). The obtained results confirm the validity of assumptions regarding main magnetic flux paths made for the inductance calculations.

\section{B. Experimental Analysis}

Apart from the FE analysis, the analytical model is also validated against experimental tests. Photos of the test bench can be seen in Fig. 7. A comparison between analytical and experimental results is reported in Table III.

Stator dc resistances are measured at ambient temperature using a Valhalla Scientific 4300B Digital Micro-Ohmmeter. The small differences between analytical and experimental results are mainly due to the random wound coil bundles, a rough estimation of contact resistances, and simplified end-winding geometry in the analytical model.

Machine inductances are measured using a QuadTech 1730 LCR Digibridge high-performance passive component tester. The measurements are found to match well with the analytical predictions. This is expected as the main inductances of the machine (air-gap and slot leakage inductances) are determined by its cross-sectional geometry, which has high manufacturing tolerances. 
TABLE III

COMPARISON OF ANALYTICAL PREDICTIONS AND EXPERIMENTAL RESUlTS

\begin{tabular}{c|c|c|c}
\hline Key performance Metrices & $\begin{array}{c}\text { Analytical } \\
\text { Model }\end{array}$ & $\begin{array}{c}\text { Experimental } \\
\text { Meas. }\end{array}$ & Unit \\
\hline Phase resistance & 202.5 & 232.8 & $\mathrm{~m} \Omega$ \\
\hline Inductance & 2.22 & 2.29 & $\mathrm{mH}$ \\
\hline Open-circuit BEMF (rms) & 48.93 & 46.32 & $\mathrm{~V}$ \\
\hline Rated output torque & 8.49 & 8.33 & $\mathrm{Nm}$ \\
\hline
\end{tabular}

To measure the fundamental iron losses, the machine shaft is allowed to freely rotate, i.e. decoupled from any external loads. The machine is fed through a power converter, and it is speed controlled by applying several speed set points. For each speed, the electrical machine input power is measured using an N4L PPA2530 precision power analyser connected at the machine terminals. As stator current is close to zero (i.e. Joule losses are negligible), the measured input power consists mostly of fundamental iron loss. The measurements are plotted against speed in Fig. 8 and are observed to be significantly larger compared to the predicted values at first. This deviation is because mechanical losses were not initially considered in the analytical model. Besides, core material machining has a considerable effect on the machine's specific core loss, causing it to be larger than the manufacturer given data [19]. To improve loss predictions, estimations of the mechanical loss are made based on [20] and a correction factor $K_{\text {corr }}=1.5$ is added to the fundamental iron loss calculation in (5).

For the open-circuit and rated load tests, the prototype machine is coupled to an external load machine with a high precision torque meter installed on the shaft between both machines. Firstly, the prototype machine's input terminals are left open, and its BEMFs are measured, with a Yokogawa DLM2024 oscilloscope, at different mechanical speeds set by the external machine. Measurements for the BEMF match very well with the analytical model as can be seen in Fig. 9.

Next, the prototype machine is connected to a power converter and operated under current control, while the load machine regulates the shaft speed at $1500 \mathrm{rpm}$ (rated value). The torque is measured under different current values and is plotted, as seen in Fig. 10 The results reveal an acceptable match between the analytical predictions and experimental results up to a rated operating point. Beyond this point, the machine begins to saturate, and the output torque deviates from the analytical model, as expected.

Finally, to validate the thermal model, thermocouples are placed at selected parts of the machine, and it is operated under rated load conditions until temperatures reach their steadystate values. The recorded temperatures for the outer stator housing and winding temperatures are $64.7{ }^{\circ} \mathrm{C}$ and $85.0{ }^{\circ} \mathrm{C}$, respectively, while the analytical predictions are $59.6^{\circ} \mathrm{C}$ and $76.4{ }^{\circ} \mathrm{C}$, respectively. The differences are acceptable considering the rough estimations of thermal resistances in the thermal network.

\section{CONCLUSIONS}

An analytical multiphysics model has been presented for the analysis of fractional slot surface PM machines. The model features the application of different techniques to enable a fast and accurate evaluation of machine performance. Detailed FE analysis and experimental tests have demonstrated the accuracy and validity of the analytical

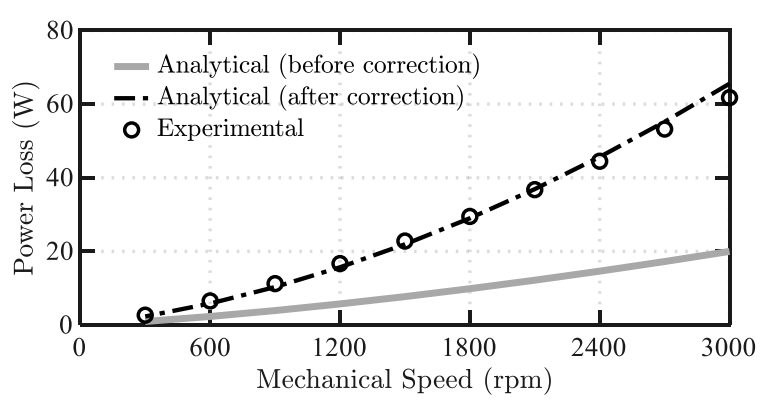

Fig. 8: Plot of no-load power loss against mechanical speed (before and after correction).

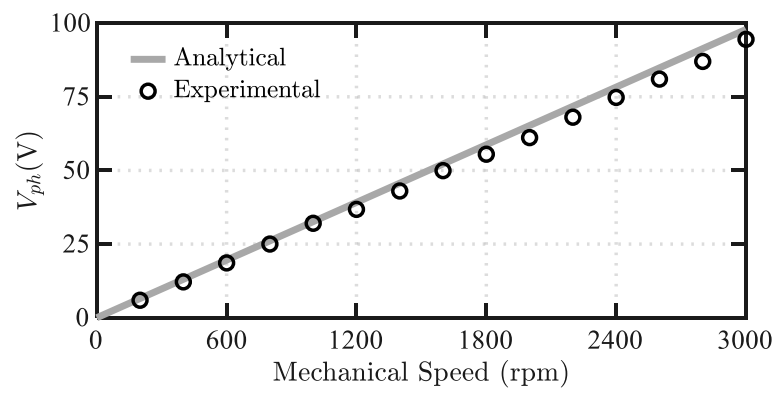

Fig. 9: Plot of open-circuit BEMF against mechanical speed.

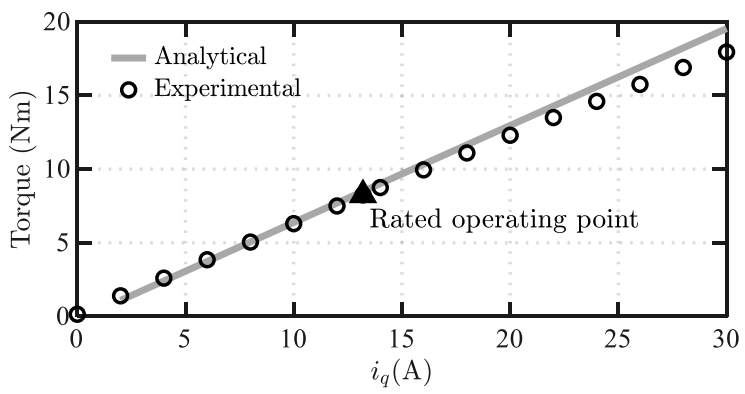

Fig. 10: Plot of machine output torque against current at rated speed.

modelling approach. Future work will be focused on employing the machine model within an optimization environment for practical machine designs.

\section{ACKNOWLEDGEMENTS}

This project has received funding from the Clean Sky 2 Joint Undertaking under the European Union's Horizon 2020 research and innovation programme under grant agreement no. 807081 .

\section{REFERENCES}

[1] A. M. EL-Refaie, "Fractional-Slot Concentrated-Windings Synchronous Permanent Magnet Machines: Opportunities and Challenges," IEEE Transactions on Industrial Electronics, vol. 57, pp. 107-121, 12010.

[2] P. Giangrande, V. Madonna, G. Sala, A. Kladas, C. Gerada and M. Galea, "Design and Testing of PMSM for Aerospace EMA Applications," in IECON 2018 - 44th Annual Conference of the IEEE Industrial Electronics Society, 2018.

[3] G. Bramerdorfer, J. A. Tapia, J. J. Pyrhonen and A. Cavagnino, "Modern Electrical Machine Design Optimization: Techniques, Trends, and Best Practices," IEEE Transactions on Industrial Electronics, vol. 65, pp. 7672-7684, 102018.

[4] A. Fatemi, N. A. O. Demerdash, T. W. Nehl and D. M. Ionel, "LargeScale Design Optimization of PM Machines Over a Target Operating Cycle," IEEE Transactions on Industry Applications, vol. 52, pp. 3772-3782, 92016. 
[5] P. Ponomarev, I. Petrov, N. Bianchi and J. Pyrhonen, "Selection of Geometric Design Variables for Fine Numerical Optimizations of Electrical Machines," IEEE Transactions on Magnetics, vol. 51, pp. 1-8, 122015

[6] B. N. Cassimere, S. D. Sudhoff and D. H. Sudhoff, "Analytical Design Model for Surface-Mounted Permanent-Magnet Synchronous Machines," IEEE Transactions on Energy Conversion, vol. 24, pp. 347-357, 62009.

[7] S. G. Min, G. Bramerdorfer and B. Sarlioglu, "Analytical Modeling and Optimization for Electromagnetic Performances of FractionalSlot PM Brushless Machines," IEEE Transactions on Industrial Electronics, vol. 65, pp. 4017-4027, 52018

[8] V. Madonna, A. Walker, P. Giangrande, C. Gerada, G. Serra and M. Galea, "Improved thermal management and analysis for stator endwindings of electrical machines," IEEE Transactions on Industrial Electronics, pp. 1-1, 2018.

[9] M. Rottach, C. Gerada, T. Hamiti and P. W. Wheeler, "A computationally efficient design procedure for actuator motors using magnetic reluctance-and thermal resistance network models," in 2012 XXth International Conference on Electrical Machines, 2012.

[10] S. A. Semidey, Y. Duan, J. R. Mayor, R. G. Harley and T. G. Habetler, "Optimal Electromagnetic-Thermo-Mechanical Integrated Design Candidate Search and Selection for Surface-Mount PermanentMagnet Machines Considering Load Profiles," IEEE Transactions on Industry Applications, vol. 47, pp. 2460-2468, 112011.

[11] Z. Q. Zhu, D. Howe and C. C. Chan, "Improved analytical model for predicting the magnetic field distribution in brushless permanentmagnet machines," IEEE Transactions on Magnetics, vol. 38, pp. 229238, 12002.

[12] D. Zarko, D. Ban and T. A. Lipo, "Analytical calculation of magnetic field distribution in the slotted air gap of a surface permanent-magnet motor using complex relative air-gap permeance," IEEE Transactions on Magnetics, vol. 42, pp. 1828-1837, 72006.

[13] D. Zarko, D. Ban and T. A. Lipo, "Analytical Solution for Electromagnetic Torque in Surface Permanent-Magnet Motors Using
Conformal Mapping," IEEE Transactions on Magnetics, vol. 45, pp. 2943-2954, 72009

[14] P. Ponomarev, Y. Alexandrova, I. Petrov, P. Lindh, E. Lomonova and J. Pyrhonen, "Inductance Calculation of Tooth-Coil PermanentMagnet Synchronous Machines," IEEE Transactions on Industrial Electronics, vol. 61, pp. 5966-5973, 112014.

[15] A. Al-Timimy, P. Giangrande, M. Degano, Z. Xu, M. Galea, C. Gerada, G. L. Calzo, H. Zhang and L. Xia, "Design and losses analysis of a high power density machine for flooded pump applications," IEEE Transaction On Industry Applications, vol. 54, no. 4, pp. 3260 3270, 2018

[16] C. Sciascera, C. Gerada, M. Galea and P. Giangrande, "Lifetime Consumption and Degradation Analysis of the Winding Insulation of Electrical Machines," in 8th IET International Conference on Power Electronics, Machines and Drives (PEMD 2016), 2016.

[17] C. Sciascera, P. Giangrande, L. Papini, C. Gerada and M. Galea, "Analytical Thermal Model for Fast Stator Winding Temperature Prediction," IEEE Transactions on Industrial Electronics, vol. 64, pp 6116-6126, 82017

[18] P. Giangrande, V. Madonna, S. Nuzzo, C. Spagnolo, C. Gerada and M. Galea, "Reduced Order Lumped Parameter Thermal Network for Dual Three-Phase Permanent Magnet Machines," in 2019 IEEE Workshop on Electrical Machines Design Control and Diagnosis, Athens, Greece, 2019.

[19] A. Al-Timimy, G. Vakil, M. Degano, P. Giangrande, C. Gerada and M. Galea, "Considerations on the Effects That Core Material Machining Has on an Electrical Machine's Performance," IEEE Transactions on Energy Conversion, vol. 33, pp. 1154-1163, 92018.

[20] J. Pyrhonen, J. Tapani and V. Hrabovcova, Design of Rotating Electrical Machines (2nd Edition), John Wiley \& Sons Ltd., 2013. 